
\title{
Social Life of Bedakampana Lingayats Living in Thalakkarai Hamlet of Anthiyur Taluk in Erode District
}

\author{
N. Kavitha* \\ PG \& Research Department of History, Vellalar College for Women (Autonomous), Thindal, Erode, Tamil Nadu, India; \\ kavi_rajkumar@yahoo.co.in
}

\begin{abstract}
India is a country with a diversified cultural heritage with a population of 1.3 billion, living in 29 states and 7 union territories. India consists of many creeds, castes, languages and religions. There are many communities living in the isolated regions of the vast and interior forests. Bedakampana Lingayat community, the followers of Lord Shiva is located in the remote Thalakkarai village in Western Ghats of Tamil Nadu, but is equally vibrant as the communities in any suburban villages of India. Despite being less explored by social scientists, they translate traditions as their vehicle to modernity. It is very fascinating to know that being exclusive in the modern governance, they strive hard to be inclusive in social and political development and do contribute to the rich diversity in culture and religion of India. Hence, this paper studies the social lives and veracity of Bedakampana Lingayats of Thalakkarai exploring their livelihood pattern, accessibility to health and nutrition, availability of education, transport and communication facilities. This paper aims at how effectively the Government Welfare Programmes such as Sarva Sihksha Abhiyan reach them, and focuses on their awareness on such schemes and the rate of utilization of the above said schemes.
\end{abstract}

Keywords: Communities, Forest, Livelihood, Rites, Rituals.

\section{Introduction}

India, the second largest democracy on world polity is a combination of diverse cultures with a population of about 1.3 billion people, living in 29 States and 7 Union Territories, speaking multiple languages and practicing various religions ${ }^{1}$. Among these, very few have made mainstream discussions in the academia for development in isolated habitations in remote regions of vast forests. Fortunately Thalakarai Village where the Bedakampana Lingayats live, is now under the control of Forest Department of Bargur. Thalakkarai is a small hamlet situated in the green forests of Western Ghats, which comes under Bargur block in Anthiyur Taluk, Erode District of Tamil Nadu. Anthiyur was recognized as a separate taluk on 22 November 2012 and is located about 70 kilometers from the district headquarters of Erode. It comprises four blocks - Anthiyur,
Athani, Bargur and Ammapet ${ }^{2}$. Thalakkarai village is located in Bargur 'B' block with a population of 1,062 where Lingayats are the dominant population with a population density of 948 (Male - 466 and Female - 482) 3 $^{3}$ This hilly area has a great floral diversity with a surplus production of timber, teak, rose, sandal woods and bamboos. Distribution of elephant herds is more in this bamboo forest. Athi (Ficus racemosa) is also prevalent here. Jackfruit is a major forest product. The fauna population consists of a wide variety of reptiles and amphibians besides birds and insects. Langur, Gaur and Indian spotted deer are the main prey animals. Carnivorous animals like leopard, bear, tiger, wild boar and wild cats are widely prevalent in this settlement. This settlement is surrounded by evergreen forests and wild life $\mathrm{e}^{4}$. This paper focuses on Bedakampana Lingayat community with special reference to the people, their lifestyle, culture and customs.

${ }^{*}$ Author for correspondence 


\section{Objectives}

The main objective of this paper is to focus on the social life of Bedakampana Lingayats residing in Thalakarai village and also the government policies which are under way to develop the region at large and community in particular.

\section{Methodology}

Though the methodology adopted for this research is primarily a descriptive and analytical approach, the study is also the outcome of based on personal interviews and data collected from Panchayat and Village Administrative office in Bargur.

\section{Bargur "B" Villages}

In the 37 villages of Bargur, Thalakkarai encompasses an area of 4046.90 beet (area of Coverage) ${ }^{5}$ with a population of 249 families, out of which 220 belong to Lingayat sect, 5 families belong to Scheduled Community and 24 families belong to Sholaga tribes ${ }^{6}$.

\section{Origin of Lingayat as in Bargur Block}

It is evident from the source ${ }^{7}$ that Bedakampana Lingayats are so-called migrants from the southwest region of Karnataka State who lived there around twelfth century A.D. Later on, they migrated from Karnataka through the hilly region of Kollegal and settled in Bargur hills which is a significant segment of Western Ghats about two hundred years ago $^{8}$. After the reorganization of the States in November 1956, Kollegal taluk which was a part of Coimbatore District till 1956 had been added to the Mysore State 9 . As Lingayat hail from Karnataka, their mother tongue is Kannada. The Lingayatas are also known as Lingawants, Lingangis, Lingadharis, Shivabhaktas and Virasaivas. They are pure vegetarians and the members of the community prefer to be called as Virasaivas. They derived their name from the Sanskrit word 'Linga' as they are ardent devotees of Lord Shiva ${ }^{10}$.

\section{Social Life}

\subsection{Lingayat Society}

The Lingayats' society is well organized with the headship of Pattakarar (Head Man). In practice, the Head man is chosen by the people of Lingayats among themselves and appointed for a period of five years ${ }^{11}$. All internal conflicts and disparities among them are investigated and solved by this Headman. So he is a much reputed person in their community people. The chosen Headman can be terminated from the post, before the tenure period in case lack of confidence among the people on him and a new Headman will be chosen. A group of elderly people assists him in performing his duties like the settlement of disputes, marital discard, unruliness and unethical behavior ${ }^{12}$. Next come Saamiyar (Priest), who presides the rites and rituals on all occasions. Thambadi (who assists the pooja work of Saamiyar) comes next. His Disciples who in-turn help Thambadi in performing the poojas ${ }^{13}$.

\subsection{Culinary Habits}

Lingayats favour vegetarian foods. In early days, it is closely related to the natural environment in which they live. Their major occupation and economic development which cater to their source of food are the integral part of their life. The staple and main food of the Lingayats is ragi. Ragikazhi (Ragi Pudding) is taken with green leaf curry or dhal water, sweet potatoes and ragi rotti taken with tamarind and chilly chutney. They also consume corn, broad bean, cowpea, green gram, black gram, field beans, forest rice, green leaves which they calls eegai rakkiri and pannaikerai in the morning and afternoon ${ }^{14}$. Government ration shop facility is available to all those people who live in that hamlet. They get all ration products in time without any delay. They are unaware of any fast food or bakery products ${ }^{15}$.

\subsection{Marriage Ceremony}

The marriage system of Lingayats is so ingeniously planned, which enables the community to identify itself as a separate sect. It forms the basis for the conjugal arrangements and as they understand the significance of their community, they regulate their marriages by following their own customs. Pair bonding is finalized after the consent of the parents and the respective caste men. Monogamy is a common practice but polygamy surfaces sporadically ${ }^{16}$. Adultery is looked upon with greater loathing by the members of the community ${ }^{17}$. Despite their habitation in the forest areas, Lingayats are well aware of their marital rights (i.e. divorce and re-marriage). Hence, divorce is also found as a common phenomenon in case of disquieted marital relations. Remarriage of widows is insisted if they are young in age, for both men and women ${ }^{18}$. In Earlier days, girls were married at their infant age itself. But now, the practice has changed due to implementation of strict law and order prohibiting child marriage. In those days, the marriage 
ceremony used to be for five days, but now-a-days it is condensed to a day. On the first day both bride and groom will bathe by applying turmeric powder on their whole body and Shikakai (Acacia Concinna) to the head. The water used for bathing of the bride and groom is taken from their holy well and is filled in five Kalasas (Earthern pots). The Pattakarar (Headman) of the village and Thambadi (who assists Poosari in pooja work) of the respected villages are invited to their houses to perform Shiva pooja ${ }^{19}$. Following this the groom is made to wear white shirt and dhothi, a red pearl chain, a linga around his neck and a Kadukkan (ear ring). Then they are taken to the homes of important caste men and then return home in the evening. Then the bride and groom's maternal uncles take them to their respective homes and are given a feast. On the second day, a Patchai Pandal (green arbor) is constructed with the help of nine forked wooden branches made from Vellai Namai (herbal plant) and nine bamboo sticks as number nine is considered as auspicious by them. The Dhobi(Washer man) then covers it with a white cloth with the help of nine members from the family of Thambadi. The Pattakarar, Saamiyar (priest) and the Thambadi of the respected families stay with them for all the five days of marriage to perform all rites and rituals. Three women are selected from the close caste men who perform rituals in the marriage and who undertake Upavasam (fasting) right from the starting of the day. To perform marriage ceremony, fifteen new earthen pots of varying are carried by the three ladies to the holy well or Oorkinaru (village well) to fetch water, which will be used for cooking sweet pongal (rice), sweets, sundal kadalai (Kala Channa) and poriyal (vegetables). After cooking, same three ladies take new earthen pots to fetch water to perform Shiva pooja. Then the Guru who lives in Bargur will be invited to solemnize this marriage. He will be the one who performs all the poojas and give theertham (sanctified water) to sanctify the ladies. The three ladies will remove the lingas from their neck and keep in their palm getting ready for the pooja. In turn, the guru will put three drops of theertham by means of vilva leafs (belpatra), which is an important aspect while doing poojas to Lord Shiva. The guru will also put banana pieces in the theertham and guru will take the Lingam from the ladies palm, replacing with three pieces of banana. These three ladies will end their fasting by taking the banana pieces with theertham. In the same way the groom will also perform the ritual to purify him before marriage. After the purification, the groom will be allowed to perform Shiva Pooja. After all the rituals, the groom has to distribute sweet pongal to all the caste men. On the third day eve- ning, by 6:00 o' clock, all the caste men will gather in his home where a grand feast was arranged for them. After that, they will start from there and reach the bride's home and settle in a place called Gibna (a place arranged for groom and his caste men). The Thambadi will now make Naaval Pandal( black jamun stalls) which is also called as Neril Pandal with nine poles, which will be adorned with Naaval leaves. Nine Thambadis will bring the bride in front of the groom and his caste menand a thin screen will be put in the midst of the bride and groom. At that time, plates with nine handfuls of rice and beetle leaves are placed by the bridal parties. Later on, this will be given to Thambadis as Dakshana (payment).The same process will be followed by the groom's side putting nine measures of rice, beetle leaf with arecanut and wedding sari in the lid of the bamboo box for the bride. Then, the bride and groom get ready for marriage. By now, the sister of the groom will perform a small rite by placing nine handful of wet sand and make a platform under the pandal and cover it with gunny bag and she will make a human like ideal with Naaval leaves which is called as Ajappa (Guardian God). By five forty five in the morning, the groom will come to the marriage stage decked in flowers and ornaments with his maternal uncle after paying his respects to the Ajappa ideal and the bride will be ushered to the marriage stage by her maternal uncle and will be made to stand on the right side of the groom. Now, the hand of bride will be placed on the groom's palm and the rice will be poured in their hands and betel leaves with arecanut and coconut will be kept. On this coconut, a Thaali (Mangal Suthra)is placed, and the parents, elders and allthe people of the community will perform poojas and bless the Thaali. After the pooja, rice, betel leaves with arecanut and coconut, of the bridal pair will be washed and groom will be given Thaali (Lakshmi symbol with thick thread which was dyed with turmeric powder) to tie on the bride's neck solemnizing the marriage. After this, a discussion regarding the expenses incurred will be discussed by the parents of the pair and as per their traditional practice in earlier times, one rupee and twenty five paise (1-1/4 rupees) will be given to five Thambadis, who in-turn will deposit it in their respective temples. Currently, twenty five paise is not in vogue, the bridal party gives two rupees to the Thambadis. Finally jaggery is broken into pieces and distributed to all the caste men and the bride and groom will come to the groom's home accompanied by his caste men. On the fifth day, a grand feast called Sammandhi Virundhu (Grand feast by both family members) takes place where varieties of food are served. The marriage ceremony ends with Manjaneerattu Vizha (Turmeric bath 
function).Peculiar customs during the marriage ceremony take place vis a vis the Thaai Maman (maternal uncle) has to make a garland from the flower called Naavilla Arali (Genugal in Karnataka language). If the Thaai Maman cannot get that particular flower on that special day, then he can make jasmine wreath to garland around the head of the bridal pair like a crown ${ }^{20}$.

One more notable custom at the time of marriage is that during the time of bride groom matching, the groom will reach the home of the bride, where all the village people will gather under their leadership of Patakarar. There the parents of the bridal pair and elderly people finalize the amount of cash to be given by the groom to the bride's family (Parisap panam). With that amount, the bride's family will make the arrangements of marriage ceremony. On the previous day of the marriage prior to all the rituals, a Soori (a crescent shape small heavy knife) is wrapped by a new piece of cloth completely except the tip through which a fresh lemon is pierced. The groom is made to hold the knife for the whole night before the day of marriage and, during all their rituals and customs. It is a custom that he must keep it in his hands till the time of marriage. In case of any personal needs, he can temporarily hand it over to his maternal uncle. This ritual depicts their vision of life that "Work is Worship". Because of this trust they consider the knife, the chief tool of their profession as an integral part of their life $\mathrm{e}^{21}$.

Another important culture is that, all the belongings of the groom which are used during the time of marriage must be kept in a bamboo box. If the groom's family does not have such box of their own, they will have to buy a new one or borrow it from someone. Only after keeping the groom's things in the box, all the other rituals commence. It is also needed that the groom must wear a yellow shirt and a white dhoti, whereas the bride wears silk or cotton sari depending upon their affordability and availability. As a part of the marriage ceremony, the maternal uncle of both bride and groom has to tie a Pattam (piece of flat copper 2 to 4 inches length) on their foreheads before the commencement of marriage ${ }^{22}$.

If there is any marital discord between the bride and the groom or if the bride is found to be guilty of any offence, then it is the responsibility of the bride's family to return the amount that they have received from the groom for marriage. If the groom is found guilty, then the amount given by his family need not be returned by the bride's parents. The marriage expenses are not high when compared with other community ${ }^{23}$.

\subsection{Rites and Rituals of the Lingayats}

\subsubsection{Valaikappu Ceremony (Baby Shower)}

The celebration before the delivery of the new born is another ceremony Lingayats observe religiously. The ceremony is called Valaikappu. It is meant for women and is celebrated during their odd pregnancy months (i.e. five, seven and nine) according to the health condition of the pregnant lady and convenience of both the family members. All the responsibilities and expenses are incurred by the family members of the wife. They perform special rituals and tap their hands and sing songs (words of blessing) to make the pregnant woman happy. During the function, colourful glass bangles in green and red will be worn by the pregnant woman and the count of the bangles are in odd numbers in the left and right hands respectively. There is also a practical reason to wear this glass bangles, the sound of bangles will intimate others about the whereabouts of the pregnant woman all the time. Elderly people bless her by applying the sacred ashes on her forehead. A simple feast with a sweet, curry made of green leaf with rice and vegetable is served to all the invitees ${ }^{24}$.

\subsubsection{Peyar Sootu Vizha (Naming Ceremony)}

If a baby is born in a hospital and when it is brought to home, both the mother and the baby are blessed by the Poosari (Priest) before they enter. The Poosari will perform certain poojas and sprinkle sacred water in and around the home. Then the Poosari has to choose a name of his own and whisper it in the ears of the new born baby three times. So, the parents convey their wishes to the Poosari who in turn keeps the same name to the baby as per the parent's wish ${ }^{25}$.

\subsubsection{Kadhani Vizha(Ear Boring Ceremony)}

The ear boring ceremony is always fixed on an auspicious day and time, which will be confirmed by Poosari. On that day, special prayers and poojas will be offered and the family members will go to the Kuladeivam temple (Clan God) and there the Mottai adithal (tonsure) and Kathani vizha (ear boring) take place in a simple manner when the baby is three months old. Earlier, they wore ear ring made of herbal plant but now- a- days, they have started using rings made of gold. For celebrating this, a small feast will be arranged by the family members for the guests ${ }^{26}$.

\subsubsection{Funeral Rites}

The Lingayats community observes an elaborate ritual for the dead. When a person passes away, the corpse will be 
placed in his home for the caste men's view. Then the body will be taken to the front yard and bathed with hot water which should be heated only by using hay. Then the body is washed with Shigakai and turmeric and is dried and adorned with proper dress. A ritual cloth, Kodi, cover the whole body. Then the body is taken in Paadai (a decorated bamboo made pall for a dead body)to the graveyard ${ }^{27}$. Baskets full of ragi, vibuthi and vilva leaves are taken to graveyard where a pooja is performed near the burial pit. Then the body is laid to rest in the pit. Earlier, the whole body in the pit was completely covered with vibuthi, but now-a-days, due to its expensiveness, only few vibuthi balls are strewn over the body as a symbolic gesture of the age long tradition. If the deceased is a man, then the Thali is taken from his wife and her right hand bangles are broken inside the burial pit. If the deceased is a married woman and her husband is alive, she is buried with her Thali and her right hand glass bangles. In the meanwhile, the elder son would have cleaned the home and the lamp lighted by him will be kept ready for the clansmen worship after returning from the graveyard. The room where the corpse was kept will be closed until a final ritual takes place. This final ritual can be conducted on the $3^{\text {rd }}, 5^{\text {th }}, 7^{\text {th }}$ or the $11^{\text {th }}$ day after consulting the caste men. On the fixed day, the priest will be invited who will give theertham (holy water) to five caste men who performed the funeral rites. During the ritual, the home is completely cleaned and the favourite dishes of the deceased will be cooked and offered. A final pooja will be done at the burial pit at night. After their return from the burial ground, two measures of ragi will be spread on the floor of the room where the deceased was kept. The favourite dishes of the deceased will be kept in a plate as offering to the deceased and the plate will be closed with a basket. The room also will be kept closed after the offerings. On the next day, the caste men will open the room to see any mark or evidence of food taken. They believe that the deceased will come to take the offering. With this, the funeral rites come to an end ${ }^{28}$.

\subsection{Health Condition}

Since lingayats live in a remote mountainous terrain, they lack easy access to medical care. When they suffer from minor ailments like fever, headache, stomachache, cough and cold, small injuries and insect bites, they heal them with their local herbal remedies. Earlier, when there was a life threatening emergency and when there was a need for advanced medical care, the patient was carried in a bamboo cradle (cloth tied between two bamboo poles) to the nearest roads, where they have access to some vehicles to go to the hospital at Anthiyur or Bargur ${ }^{29}$. Now, things have been improved considerably as Mobile Medical Team of the Primary Health Center, Bargur, makes its weekly visit on every Friday ${ }^{30}$. It has improved the health facility of the people to a great extent. However, they take care of their minor ailments like fever, headache, stomachache and insect bites through their herbal medicine. They approach the medical team only when they cannot treat it by themselves $^{31}$

Although children and adults of the village seem to be emaciated, they are not malnourished. Due to insufficient transport facility, people used to walk for many kilometers every day for their livelihood and so their calories are completely burnt and there is no symptom of obesity. They rarely fall sick since they do physical work. People in this area do not suffer from the common ailments of the city people who lead a sedentary life style (Blood Pressure, Diabetes, High Cholesterol etc) ${ }^{32}$.

\subsection{Education and Special Schemes}

Recognizing the fact that the real growth of the people living in the isolated areas can only be achieved through their knowledge of the Government policies and job schemes and by making them aware of the scientific advancements of the present world, the Government also has made some concrete steps to bring quality education to these people by opening Panchayat Union Middle School, Thalakkarai, Anthiyur block. In 1962, the Primary school was established. Later on in 2011, its rank was elevated to Panchayat Union Middle School ${ }^{33}$. There are one hundred and fifteen schools in Anthiyur block among which forty two are Middle schools, eight are High schools, eight are Higher Secondary schools and the remaining fifty five are primary schools. Among the forty two Middle Schools, one middle school is functioning in Thalakkarai ${ }^{34}$. It has helped immensely by making the community aware of special schemes that the government has provided. The Government School has a total strength of one hundred and forty six up toeighth standard. The Mid Day Meal Scheme is also implemented in this school to encourage the students to attend the classes. There is no school exceptionally for the tribal people other than this ${ }^{35}$.

The Sarva Shiksha Abhiyan scheme was introduced in this school from 2002 onwards ${ }^{36}$. In accord with this scheme, from standard one to standard four, Simplified Activity Based Learning (SABL) system is put to practice. For the students of fifth standard, Simplified Active Learning Method (SALM) is implemented. For the students from standard six to standard eight, Active Learning Method $(A L M)$ is introduced ${ }^{37}$. All these schemes are introduced by the Government to reduce the dropout ratio of this 
school and to improve the quality. Under these developmental schemes, infrastructural facilities like construction of building and classrooms, furniture purchase, construction of toilets and compound wall, purchase of materials for activity based teaching are provided. Additionally, teachers of these schools are given training twice a month on activity based teaching with the models at the training center in the Headquarters of Anthiyur block. Trainers from Chennai visit twice a month to train these teachers ${ }^{38}$. Under the scheme of Sarva Shiksha Abhiyan, Security Guard facility is also provided to the School children who are coming from long distance and in other places of the village. Children will be picked up from their home and dropped in their school through a van provided by the government. For the physically challenged people, the government is providing monthly allowances and Home Based Education for the completely disabled people is also being arranged ${ }^{39}$. The students are learning the usage of computers through the facilities provided by Computer Aided Training Centre which has been instituted to teach the children. In addition to that, Technology Club has been instituted in this school with the membership of five. The President of this club will be any Girl or boy from eighth standard along with one teaching staff as a Nodal Officer. Every year, competitions are conducted at Block level to create awareness among the students on technology. A Cluster Resource Centre has been established in the same year to conduct competitions on various topics to create awareness among the students. The winners are awarded with certificates, cash award and an overall trophy for the best school to encourage their knowledge, skill and participation. In on-line programs like Shaala Siddhi (Digital India Programme), statistical datas like the condition of infrastructure, drinking water facility, toilet facility, purchase of material tools for education are entered. The vigilant officers appointed by the Government observe all activities periodically. To get a practical exposures, the students are taken to the nearby places as a "One Day Educational Tour" arranged by government. Out of School Children (OSC) survey is conducted every year in the month of May, to check out if any of the children are retained at home. If it is found out that any child who hasnot been enrolled in the school, the officer in-charge will educate their parents about the importance of education and various schemes of Government ${ }^{40}$.

However, the Lingayats do not realise the importance of education. It is because of lack of interest and their poor economic back ground which lead to a very poor attendance rate in attending the classes. They prefer to go for jobs outside (industries or factories or to any shops) for daily wages. They attend classes only on special occasions when the government provides them with any special scholarships. The government provides scholarship of Rs.500 to the students of $5^{\text {th }}$ and $6^{\text {th }}$ standards and Rs 1000/- to the students of $7^{\text {th }}$ and $8^{\text {th }}$ standards. Since the literacy rate is very low and there is no thirst among the people to read and learn more, the community does not have a library. The teachers are taking special care to decrease the dropout rate in the schools ${ }^{41}$.

The Lingayat children's denominational identities have always affected their school experiences. Ideally, the school teacher must play a vital role in supporting the struggles of first-generation learners. As the people living here speak Kannada language, they are not interested in learning other languages. This is also considered as one of the reasons for the increasing school dropouts. Since, the language they speak is distinctly different from the medium of instructions in schools, the children often find it extremely difficult to cope with their studies and homework. This lack of language skills acts as a serious impediment to link the two linguistic experiences for the child. As they are afraid of laws, rules and regulations, girl children are normally married after eighteen years. Otherwise, they are married even before they come of age .But few of them are working as Engineers, Managers and Supervisors in private sectors $^{42}$.

Several schemes are introduced by the Government which help this community people to continue their studies. Earlier, only $25 \%$ of them appeared for the Board examinations. But now the condition has improved whereas $75 \%$ of them appear for the Board examinations. But the point to be noted here is that not even one in a family is a degree holder ${ }^{43}$. The reason given by them for this is that they cannot send their children for higher studies due to poor economic back ground. Only those who can afford are able to send their children for higher studies and that too only male child gets that opportunity. The school run by the Government here has classes upto eighth standard. For higher classes, the children have to travel for an hour to reach Anthiyur. The lack of educational institutions in the neighbourhood and non availability of transport facilities are the chief hurdles for them to continue their higher studies $^{44}$. Above all, the students strive hard to continue their studies and have great inclination towards education.

\subsection{Worship}

The Lingayats include a sub-sect called Lingoth pawar who are considered to be orthodox in their social and religious practices. They profess that a true Lingayat "worships his Ishtalinga in his hand, concentrating his own mind on it, forgetting the external world" ${ }^{45}$. Every day, 
when they wakeup early in the morning, they invoke their sacred God Lord Shiva and apply the sacred ashes on their forehead before stepping out of their homes. Their deity is also known by different names such as Manjumalai Matheshwaran, Urikkonbu Pasuveshwaran, Vadakal Madeshwaran, Pandeshwaran, Mudavela Iswaran and Maalingeshwarar. Their important and other favourite dieties are Basuveswaran, Lingeshwaran and Mariamman ${ }^{46}$. They also worship Lord Shiva's Vaagana (vehicle, the Nandhi)as their favourite diety ${ }^{47}$. Since they wear lingam held by a chain around their neck, they are called Lingayats. The person of obeisance in performing the rites and rituals is Saamiyar (Priest) who always wears Lingam from his birth to death. Samiyars observe strict rituals to maintain their sanctity; no outsiders will be welcomed to their houses. They never dine outside their village or locality and while travelling they should carry their own food and water. They worship Lord Basuveshwaran and consider cow as their sacred God. They start their day with cow worship. The remaining other sect of Lingayat people are not that orthodox or conservative. They practice pure vegetarianism and do not hesitate to accept it from outside; they are not in the habit of wearing Lingam around their neck always, but only occasionally like festivals or at the time of religious functions. The Lingayat people also prove their dedication to God by adding prefixes and suffixes to their names like Eswaran or Lingam. But the people who enter into second marriage are not permitted to perform pooja, as they follow rigid moral codes ${ }^{48}$.

\subsection{Economy}

Agriculture and cattle breeding are said to be their main occupation. People use leaves of Injam tree to scrub and clean their utensils and they live in houses with modern facilities, an outcome of Pasumai Amma Veettu Thitham. There are no bore wells, but they avail water through wells and streams in their village. The rainy season is from March to July and September to December. The most important crops are Ragi, Forest Paddy (red rice), ellu or sesame, Carum, Pyro, Shoya, Shamay and Pulses (green, bengal and black gram $)^{49}$. In the month of January, February, and March, ploughing is done and seeds are sown immediately. Crops are always sown separately, but they are harvested in regular seasons every year especially in the months of July, August and September. So the people have their food from the products that they produce ${ }^{50}$. But, they have work in their farms only for six months as they are mainly rain fed crops and for the rest of the days, people tend to work as labourers in some other's fields. Now, the youngsters have started to move to various occupations in the plains chiefly as labourers in Tiruppur hosiery field. The main and income generating occupation of these people is producing brooms by using the natural raw materials that they gather from Boli, an interior place inside the forest nearby their village. Their brooms are collected by the forest department by paying a reasonable amount ${ }^{51}$. The forest department then sells these products at the available market rate, which is usually higher than the amount they pay to the forest people. Elephants are a dreadful nuisance to the farmers who live near the forest. They hinder much of the farming activity by destroying the crops and many farmers have lost their lives. So, for the safety and security of the people, deep and broad Elephant Proof Trenches (EPT) are dug to avoid elephant attacks especially during the jack fruit season ${ }^{52}$. But now-a-days, the farmers are planting tapioca and corn in abundance due to poor rainfall and to get hay for their cattle breeding. With view of improving the poor road connectivity, the government under the Bharat Nirman Prime minister Village Transport Scheme is establishing roads to connect all the villages at the earliest, which will in turn help those people to move easily from one place to the another ${ }^{53}$.

\section{Conclusion}

Hence, the above study deals with the life and survival of the Lingayat people. It brings out the unknown factors of this hidden community on hills. The isolated and almost conservative Bedakampana Lingayatas who form the bulk of Lingayat community are very dynamic in their contribution to Indian society and culture. They are known as Virasaivas, because of their never failing zeal and unflinching firmness to observe the tenets of their religion. So the issue of their development is not progressive in-spite of all the efforts put in by the authorities of the government departments. The people living there do not opt to change their way of life, refusing to understand the values of modern education, health care and technological advancements. They still want to continue their ancient practices of depending more on forest products instead of entering into the modern world. The study shows that more and more concrete steps need to be undertaken by the Welfare Board of the Government, by the NGOs and by other social organisations to empower this Lingayat Community on par with the other rural and urban areas of the country.

\section{References}

1. Available from: https://en.m.wikipedia.org/wiki/Demographics_ of_Indiawww.worldometers.info/world-population/ india-population, 04.11.2017.

HuSS: International Journal of Research in Humanities and Social Sciences 
2. Available from: Googleweblight.com/i?u=http://www. thehindu.com/todays_paper/tp_national/tp_tamilnadu/ anthiyur, 03.11.2017.

3. Census Record as on May 2017, Panchayat Union Middle School, Thalakkarai village, Anthiyur.

4. Personal interview with Ragunathan.N, Forest Guard, In-charge, Thalakkarai Beet, Anthiyur Range, Erode Division on 03.05.2017.

5. Re Settlement Register, Survey No. 1621-1721, Village Administrative Office, BargurBlock, Erode.

6. Census Record., Op. cit.

7. Nanjundayya HV, Ananthakrishna Iyer LK. The Mysore Tribes and Castes, Volume IV, Mysore University, Mysore. 1931; 81-82.

8. Personal interview with Ragunathan.N.,Op.cit.

9. Baliga BS. Madras District Gazetteers, Coimbatore. The Director of Stationary and Printing, Government of Madras, Madras. 1966; 1.

10. Nanjundayya HV, Ananthakrishna Iyer LK. p. 81., Op. cit.

11. Personal interview with Sithalingam B, Lingayat, Agriculturist, Thalakkarai Village, Erode Division on 13.11.2017.

12. Ibid.

13. Personal Interview with Marathambadi S, Animal Poach Watcher (APW), Lingayat, Thalakkarai on 05.10.2017.

14. Personal interview with Vijaya S, Lingayat Woman, Thalakkarai on 05.10.2017.

15. Personal interview Kumar M, Ration distributor, Thalakkarai Village, Erode Division, Erode on 05.08.2017.

16. Personal interview with Chitra M, In-Charge, Anganvadi, Thalakkarai Village on 12.11.2017.

17. Marathambadi S. Op.cit.

18. Sithalingam M. Op.cit.

19. Ibid.

20. Marathambadi S. Op.cit.

21. Personal interview with Shivalingam M, Lingayat, Thalakkarai village on 18.10.2017.

22. Ibid.

23. Sithalingam M. Op.cit.

24. Vijaya S. Op.cit.

25. Personal interview with Matheshwaran S, Lingayat , Thalakkarai village on 14.11.2017.
26. Personal interview with Eswaran S, Lingayat, Thalakkarai village on 14.11.2017.

27. Personal interview with Sithalingam $\mathrm{R}$, Lingayat, Thalakkarai village on 13.11.2017.

28. Ibid.

29. Personal interview with Shivamoorthy S, Lingayat , Thalakkarai village on 13.11.2017.

30. Raghunathan N. Op.cit.

31. Personal interview with Saravanan M.B.B.S, Bargur, Primary Health Center, Erode Division on 13.05.2017.

32. Observations through interviews with the people of Lingayats, Thalakkarai village.

33. Personal interview with Maragatham K. Head Mistress, Panchayat Union Middle School, Thalakkarai village, Anthiyur Block, Erode on 10.11.2017.

34. Personal Interview with Nirmal S. Block Resource Teacher Educator, Anthiyur Block on 16.10.2017.

35. Maragatham K. Op.cit.

36. Nirmal.S. Op.cit.

37. Ibid.

38. Ibid.

39. Maragatham K. Op.cit.

40. Ibid.

41. Ibid.

42. Observation through interviews from Lingayats, Thalakkarai village.

43. Maragatham K. Op.cit.

44. Sithalingam M. Op.cit.

45. Nanjundayya HV, Ananthakrishna Iyer LK. p. 81., Op. cit.

46. Personal interview with Sithalingam J, Lingayat, Thalakkarai village on 13.11.2017

47. Ibid.

48. Marathambadi S. Op.cit.

49. Sithalingam M. Op.cit.

50. Personal interview with Murugan R, Lingayat, Thalakkarai village on 13.11.2017

51. Ibid.

52. Raghunathan N. Op.cit.

53. Ibid. 